\title{
PRACTICE
}

\section{Development of a Mentoring Course-Based Undergraduate Research Experience (M-CURE)}

Heather E. Dillon, University of Washington Tacoma

\begin{abstract}
Undergraduate research has been shown to provide numerous benefits to students. In recent years an effort to scale the experience has led to development of course-based undergraduate research that often focuses on data collection or analysis. This article describes the design of a mentoring course-based undergraduate research experience (M-CURE) that focuses on the publication and career growth aspects of the research experience. A survey of students who completed the course indicated that they appreciated both the publication and mentoring facets of the course. The first three cohorts of the M-CURE course have resulted in 83 percent of students with a viable paper for publication. Eighty-one percent of the students indicated that they were extremely or somewhat likely to attend graduate programs in the next five years.
\end{abstract}

Keywords: course-based research, CUREs, engineering, mentoring, undergraduate research experience

doi: 10.18833/spur/3/4/7

The benefits of the undergraduate research experience to all students have been well established in the literature (Bangera and Brownell 2014; Stanford et al. 2017). Research experiences for undergraduates (REUs) have been shown to increase retention and learning.

One of the most common types of undergraduate research experience is a summer internship that focuses on data collection and analysis of a research topic. One challenge that often accompanies the traditional undergraduate research experience is publishing the student work in a way that allows the student to take a leadership role. Engineering faculty find that coaching students through the publication process is not always feasible during the course of the undergraduate research experience, particularly when limited to the summer. For tenure-track faculty members at undergraduate teaching universities this challenge is critical since the publication of work is important for career progression.

Another challenge for faculty mentors is making sure the research students receive appropriate guidance on graduate school applications and career progression. This advice must be timely and is often complex for each individual student. The need to support first-generation students and underrepresented students in this process also is a critical part of improving the STEM pipeline.

The University of Portland adopted an innovative approach to address challenges with publishing and high-quality mentoring of undergraduate research students. The students took a course in the fall of their third or fourth year that focused on publishing the work they had completed as an undergraduate student and exploring the possibility of graduate studies. This article describes the design of this mentoring course-based undergraduate research experience (M-CURE) and the student experiences from the first three offerings of the class. The typical schedule for a student taking the course is shown in Figure 1.

Students are permitted to take the class after the second year of study if they wish (about 10 percent of the students do this); however, most students who complete research experiences early are hired by the faculty researchers to continue working during the subsequent academic year. 
FIGURE 1. Typical Student Progression

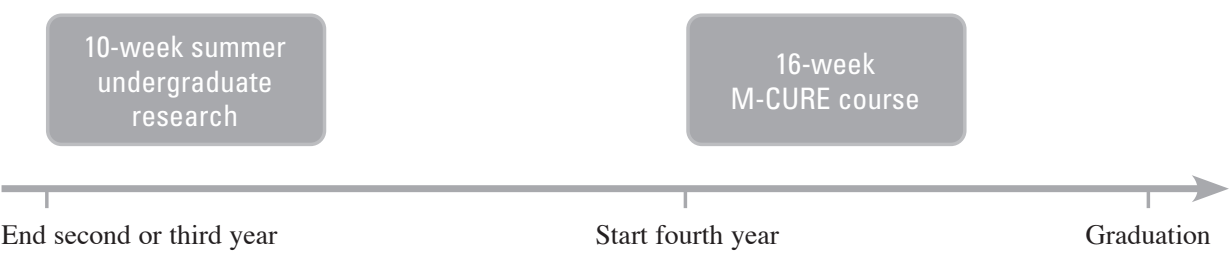

In these cases, students often postpone taking the course to increase the publication data and improve the quality of the research.

\section{Background}

Benefits to students derived from undergraduate research experiences have been explored in prior literature (Bangera and Brownell 2014; Linn et al. 2015; Lopatto 2007; Stanford et al. 2017). Bangera and Brownell (2014) argue that undergraduate research is an important way to make science more inclusive.

In recent years a shift has occurred, and many programs have implemented course-based research experiences. Most of these focus on embedding the research experience in a course to allow wider access to undergraduate research experiences. These classes are referred to as course-based undergraduate research experiences (CUREs) and have been most popular in the sciences (Brownell and Kloser 2015; Dobaria et al. 2018; Harrison et al. 2011; Lopatto et al. 2014; Russell et al. 2015; Shaffer et al. 2014). Auchincloss and colleagues (2014) provide a detailed description of what defines traditional CUREs. Corwin, Graham, and Dolan (2015) provide a research-based list of possible student learning outcomes for CUREs.

Russell and colleagues (2015) modified the CURE approach to bridge the levels of student participation across the curriculum. Other faculty groups have built seminar classes modeled on graduate program seminars to introduce students to research and reading literature (Feyrer 2017). Shortlidge, Bangera, and Brownell (2016) studied faculty perspectives on the unique challenges of teaching CUREs. These include the logistics of the research experience, the large time investment, the support structure students require, the limitations on research that may be performed, and the uncertainty of viable products. Lopatto and colleagues (2014) also analyzed the benefits and challenges of CUREs in the context of institutional support.

Mentoring of undergraduate students in an effective way has been a focus of many research teams (Colbert-White and Simpson 2017). Bradley and colleagues (2017) found evidence that multi-mentor models are beneficial to students and provide additional support for the research experience.
No prior research is available about the direct performance of a scaffolded program that includes a CURE in engineering using a multi-mentor model and professional development program. This article describes the design of a mentoring course-based undergraduate research experience that focuses on the publication and career growth aspects of the research experience.

\section{Design Methods}

The M-CURE class was designed to augment a standard summer-internship-based undergraduate research experience for engineering students. The summer research program is similar to those at most universities, with summer seminars, field trips, and design activities to build community in addition to the actual research. The University of Portland is a relatively small school with an engineering faculty of around 30 , so the size of the summer program is modest. There is a small graduate program, but most faculty rely completely on undergraduate students for research.

The students are selected for the summer program by the engineering faculty mentors, in recent years using best practices for inclusion. This includes advertising the summer positions to the entire School of Engineering student body and encouraging faculty to select first- and secondyear students whenever possible.

Over time, faculty mentors in the program observed that it was difficult for the summer research experiences to lead directly to publications. The engineering students were excellent at performing experiments and building models but rarely had enough time to begin drafting papers during the 10-week summer experience. Many of the faculty then wrote papers or worked to publish the research results independently, without the assistance of the students. It was difficult to provide an equitable level of access to guidance about graduate school applications due to variations in faculty mentoring styles.

To address these challenges a new mentoring course-based undergraduate research experience that concentrated on the publication and career growth aspects of the research experience was developed. The course was designed for students to take after completing a more traditional summer research experience, or near the end of their experience at 
the University of Portland, in the fall, when graduate applications are typically due (see Figure 1). Students who have not completed an REU at the University of Portland are welcome to take the course, and although research experience is encouraged, it is not required to take the class.

In the design of the class the relevant literature was consulted, and engineering faculty were asked to provide input about the needs to be addressed by the M-CURE course. Two key course goals were established that were important to the University of Portland program:

- Students write a research publication based on experimental or modeling work they have already completed.

- Students become familiar with possible career paths and determine whether applying to graduate programs may be helpful to them.

The course lecture material was developed using backward design (Wiggins and McTighe 2005), with more detailed learning outcomes for each course goal. The result was a three-credit semester course that met three times per week, with specific days each week reserved for different types of materials. The course material was structured to support the needs of first-generation and underrepresented student groups.

For the development of a research paper the following elements are covered over the course of the semester:

- Abstract. Lecture covers the important elements required, and students draft an abstract.

- Introduction. Lecture covers the required elements for an introduction, and students draft an introduction based on their research project.

- Background. Lecture covers the structure of a literature review and software tools for citation management and plagiarism. Students then complete a literature review and write the background.

- Methods. Lecture covers the key elements of the methods section. Students are taught how to create high-quality vector graphic diagrams of equipment and devices to include in this section. Students then generate figures and write the methods section.

- Results. Lecture covers the written elements of the results section and the best practices for generating high-quality figures, choosing tables versus figures, and statistics. Students generate the figures and write the results section of the paper.

- Conclusions and discussion. Lecture covers the important elements of writing this section and referring back to literature findings. Students then draft the conclusions section of the paper.

- Acknowledgments. Lecture covers how to structure this section and provides guidance about the groups that might be important to thank.
- Peer review process and journal submission. Lecture provides an overview of how the publishing process works and how to accept comments. Students then participate in a peer review activity by reviewing other papers written in the course. The students identify a journal for publication and work with the lead faculty member to submit the draft paper at the end of the course.

- Poster presentations and technical talks. Students are given guidance about designing a strong poster and technical talk. Students are encouraged to present the posters and then give the technical presentations to one another as part of the course.

After each section of the course the students submit drafts to the instructor and receive feedback about the individual paper elements as they progress through the class. At the end of the term the students combine the sections into a finished paper and receive additional feedback from the instructor. Then the students submit the paper they have drafted to the primary research faculty mentor for possible publication.

To be inclusive to all students, the course is open to students that have not yet completed a research experience. For these students, the course structure is designed around a literature review paper, in which they focus on providing a very detailed and comprehensive review of an engineering topic that would be appropriate for publication.

The second element of the course, focused on career planning, is handled in a similar way. As the semester progresses, the students are required to build a portfolio of materials for either graduate applications or job applications. The topics covered are listed below.

- Resumes. Students rework existing resumes to highlight research experiences and other skills valued by graduate schools.

- Personal essay. Students are coached in how to structure a strong personal essay. They develop a theme and turn in a draft essay.

- Graduate school versus other career options. Lecture covers the different types of opportunities typically pursued by engineering students. Students are asked to start a process of self-reflection to consider what type of career path they might enjoy.

- Diversity and inclusion. Students are provided information about imposter syndrome, mental health, and diversity issues. This knowledge assists some students in drafting a diversity statement if required by a graduate program.

- Graduate school advisers and research topics. Lecture covers the spectrum of graduate school options, and then students build a spreadsheet listing possible graduate schools, graduate advisers, research topics, or possible 
TABLE 1. Challenges Associated with Traditional CURE Courses

\begin{tabular}{|l|l|}
\hline Traditional CURE challenges & \multicolumn{1}{|c|}{ M-CURE methods to address } \\
\hline Logistics of class/travel & $\begin{array}{l}\text { Experimental research work is typically performed during the summer or during } \\
\text { a prior REU. }\end{array}$ \\
\hline Time investment & Leverages the time of one course instructor to benefit many research labs and projects. \\
\hline Financial constraints & Experimental research work is performed during the summer or during a prior REU. \\
\hline Expanded role of instructor & $\begin{array}{l}\text { Course instructor serves as a secondary mentor, reducing the need for both faculty } \\
\text { members to support all facets of student needs. }\end{array}$ \\
\hline Type of research that works in a course & $\begin{array}{l}\text { Experimental research work is typically performed during the summer or during } \\
\text { a prior REU. }\end{array}$ \\
\hline Uncertainty that results will be publishable & $\begin{array}{l}\text { Risk is distributed between many faculty labs and projects. } \\
\text { Course is not required in the curriculum and taken as an elective by fourth-year } \\
\text { students who have self-selected for the course. }\end{array}$ \\
\hline
\end{tabular}

Note $:$ REU $=$ Research Experience for Undergraduates. The list of challenges is adapted from the work of Shortlidge et al. 2016.

engineering firms if they believe they might prefer to work in industry.

- Graduate school funding and fellowships. Lecture covers information about typical funding mechanisms for graduate programs. Students are asked to enhance the spreadsheet they built with a list of fellowships or scholarships for which they might be well suited.

After the students turn in elements like resumes and personal statements, they are provided feedback from the course instructor. Each student meets individually with the instructor to discuss graduate programs or career options that may help them reach long-term professional goals.

The M-CURE class as structured has advantages over more traditional CURE classes that make it well suited to a small university with a summer research program in place. A summary of the challenges of traditional CURE classes is provided in Table 1.

Other benefits to the students are significant. First, the students have access to a second (alternative) research mentor in the course instructor. It may be helpful for students to see different mentoring styles. They also gain exposure to a more diverse group of mentors.

The students benefit from a very structured experience for writing the research paper. This occurs over a semester, giving students time, scaffolding, and motivation to produce a high-quality paper. The specific research skills such as literature review, creating figures, and writing are provided to all students at the same time, so individual faculty mentors are not forced to provide this separately. The students feel safer with the writing process since they are given formal rubrics and feedback over the course of the semester from someone other than the primary research mentor. They receive support from the cohort of students taking the class and writing papers at the same time. Students paper results are of high quality, making it more likely that they will be the first author on the final publication.

The course also provides a highly structured approach to building a career portfolio. Navigating the graduate application process is daunting, particularly for first-generation students. Taking time to draft resumes and personal statements with faculty feedback as part of the course leads to a polished portfolio of materials that allows students to feel comfortable in the application process even if they ultimately choose other career paths.

The primary drawback of the M-CURE is the small scale of the course. Unlike many traditional CUREs, it has not been designed to scale to large course sizes, and more than 20 students in a class of this type would create a significant burden on the instructor. For this reason, the M-CURE course structure may be most suitable for smaller universities.

\section{Assessment Methods}

To evaluate the performance outcomes of the M-CURE course a student survey was developed. Other known outcomes, like the number of student publications, were collected. The number of students who have completed the M-CURE course is very small, so the results have no statistical significance, but the insights about the course may be helpful to universities that would benefit from an M-CURE-style course.

The survey was designed and sent to the students who completed the course in the first three years the class was offered. The survey asked students to self-report some information about their current career paths and to rate specific aspects of the class on a Likert scale. 
TABLE 2. Summary of Survey Responses about the Course

\begin{tabular}{|c|c|c|c|c|c|}
\hline & Strongly agree & Somewhat agree & $\begin{array}{c}\text { Neither agree } \\
\text { or disagree }\end{array}$ & $\begin{array}{l}\text { Somewhat } \\
\text { disagree }\end{array}$ & $\begin{array}{l}\text { Strongly } \\
\text { disagree }\end{array}$ \\
\hline $\begin{array}{l}\text { I have spent significant time } \\
\text { considering my short-term career } \\
\text { goals ( } 1-5 \text { years). }\end{array}$ & $85 \%$ & $15 \%$ & $0 \%$ & $0 \%$ & $0 \%$ \\
\hline $\begin{array}{l}\text { I have spent significant time } \\
\text { considering my long-term career } \\
\text { goals ( } 5-15 \text { years). }\end{array}$ & $54 \%$ & $46 \%$ & $0 \%$ & $0 \%$ & $0 \%$ \\
\hline $\begin{array}{l}\text { I feel competent writing a scientific } \\
\text { research paper for publication. }\end{array}$ & $62 \%$ & $38 \%$ & $0 \%$ & $0 \%$ & $0 \%$ \\
\hline $\begin{array}{l}\text { I have worked to develop a deeper } \\
\text { understanding of my own strengths } \\
\text { and weaknesses. }\end{array}$ & $61 \%$ & $35 \%$ & $4 \%$ & $0 \%$ & $0 \%$ \\
\hline $\begin{array}{l}\text { I feel competent developing and } \\
\text { presenting a scientific research } \\
\text { poster for publication. }\end{array}$ & $77 \%$ & $23 \%$ & $0 \%$ & $0 \%$ & $0 \%$ \\
\hline $\begin{array}{l}\text { I understand the research publication } \\
\text { process and how to engage with } \\
\text { journals and conferences. }\end{array}$ & $31 \%$ & $65 \%$ & $4 \%$ & $0 \%$ & $0 \%$ \\
\hline $\begin{array}{l}\text { I understand the process of applying } \\
\text { for graduate programs and finding } \\
\text { funding for graduate studies. }\end{array}$ & $81 \%$ & $19 \%$ & $0 \%$ & $0 \%$ & $0 \%$ \\
\hline $\begin{array}{l}\text { I am comfortable performing an } \\
\text { engineering research literature search } \\
\text { and structuring it for publication. }\end{array}$ & $65 \%$ & $35 \%$ & $0 \%$ & $0 \%$ & $0 \%$ \\
\hline $\begin{array}{l}\text { I am comfortable with failure in } \\
\text { the context of engineering research } \\
\text { and know how to use it to identify } \\
\text { opportunity. }\end{array}$ & $65 \%$ & $31 \%$ & $4 \%$ & $0 \%$ & $0 \%$ \\
\hline $\begin{array}{l}\text { I am comfortable developing a } \\
\text { research question and exploring it } \\
\text { using common engineering research } \\
\text { methods. }\end{array}$ & $50 \%$ & $50 \%$ & $0 \%$ & $0 \%$ & $0 \%$ \\
\hline
\end{tabular}

Note: $N=26$

To assess the student direct outcomes, faculty mentors were contacted to quantify how many papers had been published and, when possible, to report on the career paths of the students with whom they had worked.

\section{Results}

The survey was completed by 26 students out of a possible 29. They were asked to self-report if they felt they belonged to a special group. A total of 14.3 percent self-reported as first-generation students, and 50 percent indicated they were part of an underrepresented group in engineering. Of the respondents, 62 percent were female.

The students were asked to rank how they felt the research course had influenced specific learning objectives using a Likert scale. The results are shown in Table 2. In each case the students overwhelmingly chose "strongly agree" or "somewhat agree" with the course outcomes. The strongest agreement aligned with the course objectives of professional development and the graduate school application process.

The next question focused on student skills: "What research-related skills did you acquire as part of the EGR 431 course? What made those skills important to your career?" A summary of the top 50 words in the student responses is shown in Figure 2 and included literature, information, and process. A more detailed review of student comments found themes of paper writing, with a specific focus on writing for research publications. A few helpful student responses are shown below.

- "The main research-related skill I acquired as part of the course - taking a research project with many different components and nuances and learning to transform it into a succinct but thorough and understandable paper for the broader computer science community. [Now, ] as a graduate student, that skill is very important as my 


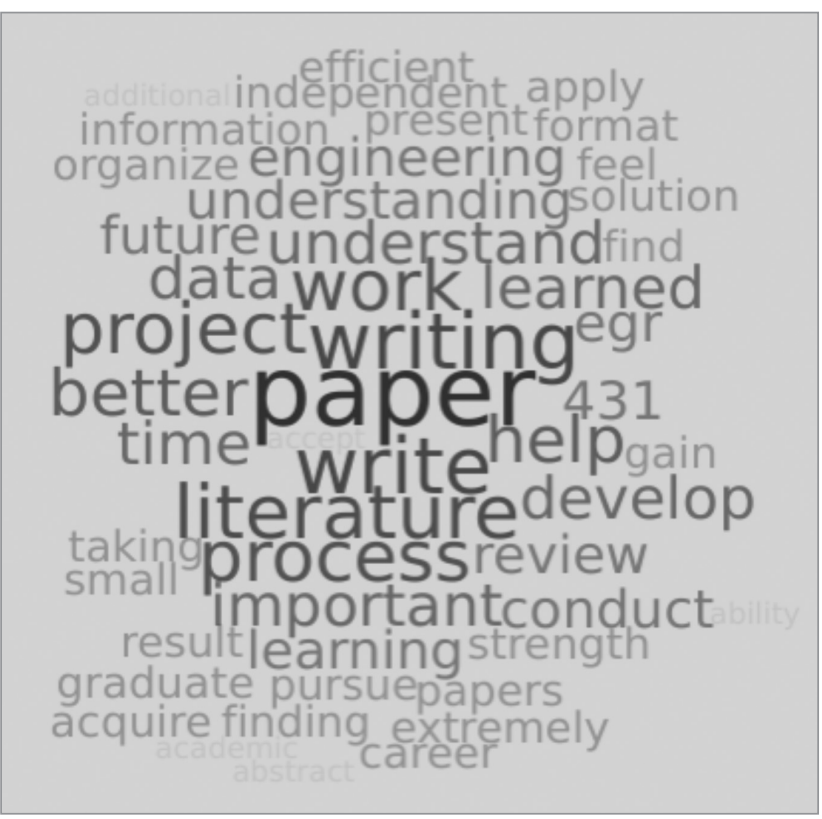

FIGURE 3. Student Comments about Career



main tasks involve performing research and then writing up reports and papers to explain the projects and findings."

- "I became very good at crafting a research paper with the appropriate vocabulary and syntax. Not only did this develop my ability to communicate intelligently in my paper, but to others in person as well. While I ended up not pursuing the graduate school path quite yet, I believe this helped during the interview process greatly."

The students were then asked, "How did this course change your outlook about your future career?" The word themes that emerged are shown in Figure 3 and included career, research, and future. A more detailed review of the student comments identified themes about graduate programs, particularly finding the confidence to apply to programs after completing the course. A few characteristic student responses are shown below. Several of the student comments illustrate the challenge of addressing the selflimiting ideas about graduate school of some students.

- "This course cemented my desire to attend grad school. I was also discovering what I wanted to do long term in my career and this course helped me pursue that desire."

- "I originally thought I wasn't a good enough student to pursue graduate school, and that it would be too expensive anyway. This class outlined all the options for applying and paying for it, and made me feel that I deserved it as a student. [The instructor] simplified the intimidating process into understandable, small pieces and now I've applied to a handful of schools. This class established research as a potential career path for me, not only in graduate school but potentially afterward. Most of all, the class encouraged me to think bigger about my future career."

- "Before taking the course, graduate school seemed like a big black box. I didn't really know how to get there and what to expect if I did get there. This course was very helpful in breaking down the steps for applying to graduate school into manageable, concrete tasks. The course also helped me gain a better understanding of the inner workings of academia (e.g., finding an advisor, funding, etc.)."

The students were then asked to comment on the role of the multiple mentors used by the M-CURE course. "Do you consider the research faculty member(s) and instructors you worked with as part of this course to be mentors? How did they influence your thinking about your future career?"

- "Absolutely. My research faculty advisor was always available to answer any questions I had, and did not allow me to talk down to or doubt myself. They promoted me to think outside the box with my research project and accept/work around any difficulties that arose. My research advisor had me seriously consider the future I wanted from engineering and worked to give me the skills to achieve my goals. They made me feel more confident about my skills and supported my growth throughout the research process."

- "I most definitely consider [the instructor] to be a mentor. She was open about her experiences in college and graduate school and this was so helpful in understanding what a potential path could really look like. I liked hearing from a woman her experiences in engineering, the challenges and self-doubt she faced, because those are feelings I often feel and we all struggle with. Personal accounts and conversations were extremely valuable." 
TABLE 3. Summary of Survey Responses about Future Scenarios

\begin{tabular}{|l|c|c|c|c|c|}
\hline & Extremely likely & Somewhat likely & $\begin{array}{c}\text { Neither likely } \\
\text { nor unlikely }\end{array}$ & $\begin{array}{c}\text { Somewhat } \\
\text { unlikely }\end{array}$ & $\begin{array}{c}\text { Extremely } \\
\text { unlikely }\end{array}$ \\
\hline $\begin{array}{l}\text { I am planning to attend graduate } \\
\text { school in the next five years. }\end{array}$ & $61 \%$ & $19 \%$ & $8 \%$ & $4 \%$ \\
\hline $\begin{array}{l}\text { I am planning to work in a traditional } \\
\text { engineering career in my future. }\end{array}$ & $35 \%$ & $46 \%$ & $15 \%$ & $4 \%$ & $0 \%$ \\
\hline $\begin{array}{l}\text { I am planning to pursue a service } \\
\text { career in the next few years } \\
\text { (Peace Corps, etc.). }\end{array}$ & $4 \%$ & $16 \%$ & $42 \%$ & $19 \%$ & $19 \%$ \\
\hline $\begin{array}{l}\text { I am planning another option } \\
\text { for my career. }\end{array}$ & $4 \%$ & $19 \%$ & $23 \%$ & $23 \%$ & $31 \%$ \\
\hline
\end{tabular}

Note: $N=26$

TABLE 4. Student Papers and Posters Published

\begin{tabular}{|l|c|c|}
\hline Student group & $\begin{array}{c}\text { Number of published, peer-reviewed, } \\
\text { conference or journal papers }\end{array}$ & $\begin{array}{c}\text { Number of poster } \\
\text { presentations }\end{array}$ \\
\hline 2016 M-CURE cohort (10 students) & 8 & 10 \\
\hline 2017 M-CURE cohort (8 students) & $4+2$ submitted & 8 \\
\hline 2018 M-CURE cohort (11 students) & $2+8$ pending & 10 \\
\hline
\end{tabular}

- "Yes I would 100 percent say the professors I interacted with throughout the research process are mentors for myself and my education moving forward. They influence me by encouraging me to chase my passion which has led me to believe that higher education in a focused engineering field is something I want in my future."

The students were then asked to provide feedback about how they are currently thinking about future plans. Most students indicated they were planning to attend graduate school in the next five years. Table 3 includes a summary of responses for this question.

The final metric gathered was the number of student papers published in peer-reviewed conference proceedings or journals. The time required for publication made this data challenging to gather. Eight papers out of a possible 10 have been published from the first cohort of students. The second cohort has 6 papers pending or published. Faculty members from the most recent cohort estimated that 10 papers would be submitted for publication. The total numbers of papers by cohort are shown in Table 4 .

The student papers were published in a broad list of journals and conference proceedings, often influenced by faculty preferences. These venues included the following:

- Environmental Engineering Science

- Frontiers in Heat Transfer

- Heat Transfer Research

32 Scholarship and Practice of Undergraduate Research
- Journal of Environmental Engineering

- Journal of Green Building

- LEUKOS, The Journal of the Illuminating Engineering Society

- Smart Grid and Renewable Energy

- American Society for Engineering Education Annual Conference

- American Society of Mechanical Engineers International Mechanical Engineering Congress (multiple papers)

- Proceedings of the International Modal Analysis Conference (IMAC) and Exposition on Structural Dynamics (multiple papers)

- International Conference on Distributed Computing Systems Workshop

- World Environmental and Water Resources Congress

- Journal of Visualization (under review)

- Journal of Water and Health (under review)

- Computer Applications in Engineering Education (under review)

Student posters were presented at a range of local to national events, but highlights included the Council on Undergraduate Research Posters on the Hill event (two posters), the National Conference on Undergraduate Research (multiple posters), and poster presentations at the NASA Ames Research Center.

Students reported enrollment in graduate programs at University of California, Berkeley; University of Washington; University of Notre Dame; University of Colorado 
Boulder; Colorado School of Mines; Colorado State University; University of California, Davis; University of California, Los Angeles; University of British Columbia; and San Diego State University.

Future work should include a more comprehensive assessment of changes in the understanding and perceptions of students with the use of a pre-course survey and a control group. A larger sample size of students also would better support the preliminary results. These changes were not feasible for this academic cycle but could be implemented in the future by others who consider the M-CURE approach.

\section{Conclusions}

This article describes the design and development of a high-impact M-CURE focused on mentoring students in relation to career objectives and paper writing. The student survey results indicate that the course goals have been well met by scaffolded paper writing and career portfolio development.

Many traditional CURE classes that align with summer undergraduate research experiences have strong outcomes (Corwin et al. 2015). This is valuable for scaling, but higher-impact outcomes are more difficult to achieve in CUREs. The M-CURE described has the ability to facilitate very high-impact student outcomes, including development of self-authorship, increased tolerance for obstacles, increased project ownership, and increased access to faculty mentoring.

The first three cohorts of the M-CURE course have resulted in 83 percent of students with a viable paper for publication. A total of 81 percent of the students indicated they were extremely or somewhat likely to attend graduate programs in the next five years. Although the course was very successful, there were several lessons learned during the implementation. The structure of the class may need to be adjusted, as each cohort of students has different needs. Flexibility in the research paper topics allows students without a more formal research experience to participate.

The transferability of the M-CURE model to other universities should be explored. For small- to moderate-size programs, this model has been successful at transitioning students from REUs to research publication. The preliminary results indicate that an M-CURE course may be a good option for extending the research and mentoring experience of undergraduate students at other teaching universities, while also providing a beneficial structure for faculty new to undergraduate research.

\section{References}

Auchincloss, Lisa Corwin, Sandra L. Laursen, Janet L. Branchaw, Kevin Eagan, Mark Graham, David I. Hanauer, Gwendolyn Lawrie, et al. 2014. "Assessment of Course-Based Undergraduate
Research Experiences: A Meeting Report.” CBE-Life Sciences Education 13: 29-40. doi: 10.1187/cbe.14-01-0004

Bangera, Gita, and Sara E. Brownell. 2014. "Course-Based Undergraduate Research Experiences Can Make Scientific Research More Inclusive." CBE-Life Sciences Education 13: 602-606. doi: 10.1187/cbe.14-06-0099

Bradley, Evan D., Michelle Bata, Heather M. Fitz Gibbon, Caroline J. Ketcham, Brittany A. Nicholson, and Meagen Pollock. 2017. "The Structure of Mentoring in Undergraduate Research: Multi-Mentor Models." Scholarship and Practice of Undergraduate Research 1(2): 35-42. doi: 10.18833/spur/1/2/12

Brownell, Sara E., and Matthew J. Kloser. 2015. "Toward a Conceptual Framework for Measuring the Effectiveness of Course-Based Undergraduate Research Experiences in Undergraduate Biology.” Studies in Higher Education 40: 525-544. doi: 10.1080/03075079.2015.1004234

Colbert-White, Erin, and Elizabeth Simpson. 2017. "A Workbook for Scaffolding Mentored Undergraduate Research Experiences in the Social and Behavioral Sciences." International Journal of Teaching and Learning in Higher Education 29: 309-380. https://eric.ed.gov/?id=EJ1146144

Corwin, Lisa A., Mark J. Graham, and Erin L. Dolan. 2015. "Modeling Course-Based Undergraduate Research Experiences: An Agenda for Future Research and Evaluation." CBE-Life Sciences Education 14 (1): es1. doi: 10.1187/cbe.14-10-0167

Dobaria, Archana S., Kimberly A. Coble, Le Alejandra, Katie Berryhill, Kevin M. McLin, and Lynn R. Cominsky. 2018. "Impacts of a Course-Based Undergraduate Research Experience in Introductory Astronomy Using Robotic Telescopes." 232nd Meeting of the American Astronomical Society, id. 118.04. http:// adsabs.harvard.edu/abs/2018AAS...23211804D

Feyrer, James. 2017. "Undergraduate Research in the Dartmouth Economics Department." Journal of Economic Education 48: 306-309. doi: 10.1080/00220485.2017.1353463

Harrison, Melinda, David Dunbar, Lisa Ratmansky, Kimberly Boyd, and David Lopatto. 2011. "Classroom-Based Science Research at the Introductory Level: Changes in Career Choices and Attitude." CBE-Life Sciences Education 10: 279-286. doi: 10.1187/cbe.10-12-0151

Linn, Marcia C., Erin Palmer, Anne Baranger, Elizabeth Gerard, and Elisa Stone. 2015. "Undergraduate Research Experiences: Impacts and Opportunities." Science 347: 1261757. doi: 10.1126/ science. 1261757

Lopatto, David. 2007. "Undergraduate Research Experiences Support Science Career Decisions and Active Learning." $C B E-$ Life Sciences Education 6: 297-306. doi: 10.1187/cbe.07-06-0039

Lopatto, David, Charles Hauser, Christopher J. Jones, Don Paetkau, Vidya Chandrasekaran, David Dunbar, Christy MacKinnon, et al. 2014. "A Central Support System Can Facilitate Implementation and Sustainability of a Classroom-Based Undergraduate Research Experience (CURE) in Genomics." CBE-Life Sciences Education 13: 711-723. doi: 10.1187/cbe.13-10-0200

Russell, James E., Allison R. D'Costa, Clay Runck, David W. Barnes, Alessandra L. Barrera, Jennifer Hurst-Kennedy, Elizabeth B. Sudduth, et al. 2015. "Bridging the Undergraduate Curriculum Using an Integrated Course-Embedded Undergraduate 
Research Experience (ICURE)." CBE-Life Sciences Education 14(1): ar4. doi: 10.1187/cbe.14-09-0151

Shaffer, Christopher D., Consuelo J. Alvarez, April E. Bednarski, David Dunbar, Anya L. Goodman, Catherine Reinke, Anne G. Rosenwald, et al. 2014. "A Course-Based Research Experience: How Benefits Change with Increased Investment in Instructional Time." CBE-Life Sciences Education 13: 111-130. doi: 10.1187/ cbe-13-08-0152

Shortlidge, Erin E., Gita Bangera, and Sara E. Brownell. 2016. "Faculty Perspectives on Developing and Teaching CourseBased Undergraduate Research Experiences." BioScience 66: 54-62. doi: 10.1093/biosci/biv167

Stanford, Jennifer S., Suzanne E. Rocheleau, Kevin P. W. Smith, and Jaya Mohan. 2017. "Early Undergraduate Research Experiences Lead to Similar Learning Gains for STEM and Non-STEM Undergraduates." Studies in Higher Education 42: 115-129. doi: 10.1080/03075079.2015.1035248

Wiggins, Grant P., and Jay McTighe. 2005. Understanding by Design. Alexandria, VA: Association for Supervision and Curriculum Development.

\section{Heather E. Dillon}

University of Washington Tacoma, hedillon@uw.edu

Heather Dillon is a professor of mechanical engineering at the University of Washington Tacoma, where her research team is currently working on renewable energy systems, lighting, energy efficiency in buildings, fundamental heat transfer studies, and engineering education. She is currently the chair of the CUR Engineering Division and recently served as the Fulbright Canada Research Chair in STEM Education at the University of Calgary, Alberta. Before joining academia, Dillon was a senior research engineer for the Pacific Northwest National Laboratory working on energy efficiency and renewable energy systems, where she received the US Department of Energy Office of Science Outstanding Mentor Award. During her time at the University of Portland, she received the Provost's Award for Outstanding Undergraduate Research Faculty Member and the Outstanding Scholarship Award.

\section{CUR's Excellence in Mentoring book}

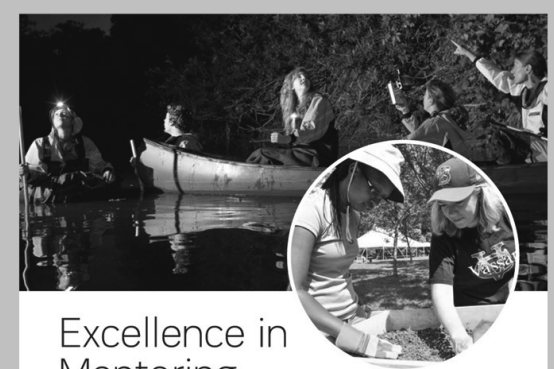

Mentoring Undergraduate Research

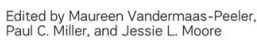

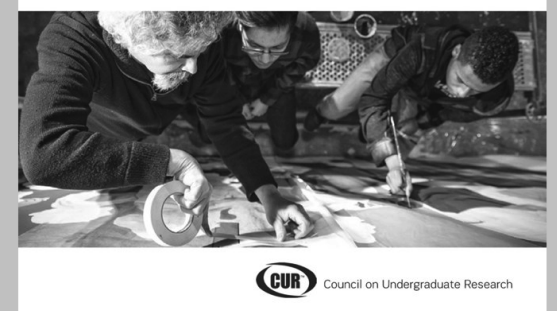

Excellence in Mentoring Undergraduate Research incorporates diverse perspectives on mentoring undergraduate research, including work from scholars at many different types of academic institutions in Australia, Canada, the United Kingdom, and the United States. It strives to extend the conversation on mentoring undergraduate research to enable scholars in all disciplines and a variety of institutional contexts to critically examine mentoring practices and the role of mentored undergraduate research in higher education.

To order, visit the CUR Bookstore (https://bit.ly/CURbkstore) 